\title{
Contributions of an integrated genre theory of text and context to teaching LSP
}

Dacia Dressen-Hammouda

\section{(2) OpenEdition}

1 Journals

Electronic version

URL: http://journals.openedition.org/asp/1306

DOI: 10.4000/asp.1306

ISBN: 978-2-8218-0392-3

ISSN: 2108-6354

Publisher

Groupe d'étude et de recherche en anglais de spécialité

Printed version

Date of publication: 1 May 2003

Number of pages: $73-90$

ISSN: 1246-8185

\section{Electronic reference}

Dacia Dressen-Hammouda, "Contributions of an integrated genre theory of text and context to teaching LSP », ASp [Online], 39-40 | 2003, Online since 11 May 2010, connection on 21 December 2020. URL : http://journals.openedition.org/asp/1306 ; DOI : https://doi.org/10.4000/asp.1306

This text was automatically generated on 21 December 2020.

Tous droits réservés 


\title{
Contributions of an integrated genre theory of text and context to teaching LSP
}

\author{
Dacia Dressen-Hammouda
}

\section{Introduction}

1 Genre has become another modern-day buzzword in the LSP community, where its methodological usefulness for research and teaching has been largely recognized. However, at a time when ESP practitioners, in France and elsewhere, are able to usefully draw from a number of approaches, such as Enunciation Theory (Lapaire \& Rotgé 1992), Systemic Functional Grammar (Banks 2002), or more recently, Appraisal Theory (Martin 2000), we might rightly ask what the descriptive analysis of genre can continue to contribute to LSP. Or has it, as a model for research and pedagogy, simply reached its limits of novelty and growth?

2 How we address this issue is closely tied to a central issue in LSP, namely, how we seek to make our students "professional". Today, we know that linguistic competence - and professionalization - occur only when the learner has acquired a wide range of overlapping competencies: terminological and grammatical, of course, but also discoursal, rhetorical, strategical, situational, sociological, and ideological. As noted by genre theorist David Russell (1997: 233), “experts don't merely know and apply rules, [...] they constantly recreate and reinterpret them in dynamic social-historical conditions." In this sense, being linguistically competent goes well beyond knowing the "mere structure" of language and includes mastering a wide range of knowledge(s) that allow individuals to actively and efficiently participate in the specific social structures around them. Recent developments in genre research respond to such pedagogical needs by identifying and describing the contexts within which knowledge structures evolve and are made available to users. 
Genre scholarship over the years has been and continues to be a quickly growing, highly interdisciplinary and controversial field. While a number of traditions have substantially developed the notion of genre (Hyon 1996), it is today an increasingly complicated movement, involving much crossover and borrowing from a variety of academic disciplines: EAP and applied linguistics, LSP and professional discourses, research in L1 \& L2 writing, composition theory, new rhetoric, the rhetoric of science and of the professions, anthropology, ethnography, sociology, and socio-cognitive psychology. Undeniably, genre practitioners have long had to contend with the charge that genre research is too disparate a practice to provide a single theory of social-linguistic behavior, let alone a discipline in its own right.

Nonetheless, arguments for using the genre approach to respond to LSP needs are found precisely in the consequences of genre's inherent interdisciplinarity and broad scope. In particular, it has led genre scholars to become interested in a multimodal exploration of the fundamental relationship between text and context. An important result of this research is the conviction that we do not learn to simply use language patterns; we learn to use them in complex socio-cultural situations from which generic language patterns are indissociable. As Eggins and Martin (1997: 251) have noted, "Texts are not a neutral encoding of a natural reality, but [are] semiotic constructions of socially constructed meanings." Context is what makes the text intelligible to the reader; without it, neither the motivations for meaning nor the more implicit aspects of language could be grasped. In this sense, we are able to fully understand the meaning of text only because we also draw on its social, historical, and ideological contexts.

In this sense, genre is not merely "text", but is "text-and-context". This integrative depiction is now prevalent in current cross-disciplinary understandings of genre, ${ }^{1}$ and is aptly illustrated by Günther and Knoblauch (1995):

Communicative genres are not to be separated from their social structural features. They are links between subjective stocks of knowledge and the social structures of a community. ... On one hand they facilitate the transmission of knowledge by guiding the interactants' expectations about what is to be said. On the other hand they are the sediments of socially relevant communicative processes, as only those processes may be expected to be fixed into genres which are of some relevance to the social actors (6).

6 Thus moving away from merely describing language patterns and variation, genre researchers have become interested in investigating context as a way of providing an explanation for why texts look like they do, what particular linguistic choices are available to the user, and what meaning, purpose and use they have for their users (Lassen 2003).

7 The results of this research are three-fold. To begin, it complicates our view of genre, whose identifiable textual patterns are seen to result from the complex relations of individuals interacting together, sharing talk, text, actions, ideologies, identities, beliefs and ideas over time. Further, it complicates our research methods by informing us about new methodologies for understanding professional discourse (Dudley-Evans \& St John 1998); about how the workplace functions (Gunnarsson, Linell \& Nordberg 1997); about the evolution of professional discourses (Bazerman 1988; Salager-Meyer 1998; Atkinson 1999; Magnet 2001); about the way texts are constructed and received, and identities are built (Prior 1998, Ivanic 1998); about genre as ideological critique (Fairclough 1992, Huckin 2002) or as recontextualization (Linell 1998, Ravotas \& Berkenkotter 1998, Dressen 
2002). Finally, this research also complicates the language teacher's role in the classroom, by raising the question of what practitioners ought to know about what they're teaching (Freedman 1999, Swales 2000). Clearly, research on genre's complexity invites us to have considerable knowledge about the communities whose discourses we teach, including an understanding of their participants' densely situated, meaning-making activities (e.g., Beaufort 2000, Geisler 2001), and to work toward integrating this complexity into the classroom. By unifying organized language activity into a coherent account of both text and context, an integrated approach to genre may help students better prepare for the challenges they will face in the professional world.

8 In this article, I will first review recent socio-cultural contributions to genre theory that refine the notion of "context". Such work on context is an important factor in pinpointing how text reflects the system of values that structures it, and which is itself constructed and maintained by text. Understanding how text and context are interrelated is important for determining how best to develop professional linguistic competence in the classroom. I will then describe a pedagogical model that uses an integrated approach to genre for developing multi-range competencies in LSP, called "Directed Communicative Modeling".

\section{Genre as text-and-context: The problem of identifying context}

9 The epistemological underpinnings of genre as "textual regularities" are well-established among LSP practioners, situated as they are within a solid foundation of over 40 years of research in applied and text linguistics, beginning with Barber and Halliday et al. in the early 1960s (Swales 1988; Biesenbach-Lucas 1995; Dudley-Evans \& St. John 1998), and further bolstered by later linguistic research on genre (Halliday \& Hasan 1985, Swales 1990; Bhatia 1993). What we take "context" to be, on the other hand, is foreseeably less straightforward.

10 Indeed, the concept of context is widely recognized for its difficulty, as demonstrated by a number of publications. ${ }^{2}$ Nonetheless, genre researchers from both rhetorical and linguistic traditions have increasingly argued for the need to develop research and teaching projects that combine both contextual and textual approaches. ${ }^{3}$ In principal, a large consensus now recognizes the necessity of an integrated approach to genre; in practice, however, the uptake has been somewhat slower.

11 Whereas research in linguistic genre has remained closely focused on genre's more textual properties, significant methodological contributions to analyzing context can be taken from recent research in rhetorical genre. By incorporating relevant aspects of socio-cognitive theories, rhetorical genre allows us to more concretely theorize about the nature of context - and in consequence, about its reciprocal association with text. Increasingly complex accounts of context allow us to view genre as the linguistically and cognitively structured relationship existing between individuals, which binds them to their various social groups. Genre's stabilized textual properties help individuals translate the realities inherent in working, acting and being together.

After reviewing recent developments of context, I will synthesize certain of its aspects into an LSP-oriented description of genre, advocating a detailed investigation of both text and context. It is clear that, however necessary or fascinating studies of context may be, 
with their detailed case studies or larger socio-historic and ethnographic investigations, a disproportionate analysis to the detriment of a careful investigation of text would lessen genre's usefulness for LSP, by leading us to concentrate more on the general roles of texts rather than on their particular details (Barton 2002).

\section{Dialogue as context}

13 In many respects, Bakhtin's $(1981,1986)$ theories about dialogism are at the center of what has retrospectively been called "genre's communicative turn" (Berkenkotter 2001) and the related move to explore the relationship between text and context (e.g., Miller 1984). Fairclough (1992) has described dialogism as the process through which speech events or text are produced and mediated through their relationship with prior discourses. Accordingly, all discourse, including writing, is considered to result from

a dynamic, functional, intersubjective process of reciprocal negotiation among writers and readers, in which discourse mediates the interactions between conversants. (Russell 1997: 507, emphasis added)

The intersubjective process of reciprocal negotiation, or dialogue, acts as the backdrop to and source of ongoing discourse and text. Here, context is not considered to be some underlying conceptual schema, independent of discourse and text. Rather, the dialogue is the context. In this sense, dialogism goes further than earlier social theories in resolving the dichotomous split between text and context, for it does not consider there to be any conceptual bracketing between text and context (Russell 1997). Because the text or discourse does not reflect a situation - it is the situation (Nystrand 1986) - dialogism allows us to understand context as resulting from the intertextual relations linking discourse, individuals and society.

\section{The intertextual genre system and recontextualization as context}

15 As a natural extension of dialogism, intertextuality provides a framework for understanding context, by describing how genres and their users dialogically relate to one another both synchronically and over time. This framework enables us to see the relationship between written and spoken activities as an organized, communicative chain, like in an engineering consulting firm where a proposal sent to a client is the outcome of many linked genres: oral, written, and electronic (Gunnarsson 1997). Such genres are held together by a series of discursive links or "intertextual chains" (Linell 1998: 149) within a "genre system" (Bazerman 1994: 80). As observed by Berkenkotter (2001), genre systems organize workplaces, and much of the work is carried out through them. ${ }^{4}$ Genre systems characterize and organize individuals' discursive activity by locating it within a specific domain, thereby giving it meaning.

However, while the rhetorical concept of genre system pushes us toward appreciating the intertextual macro-environment in which genres take shape and are used, it does not show us how text and context are intimately entwined. True to the grounded needs of LSP in descriptive linguistics, we also need to closely view genre's intertextuality from a more micro-level, or textual, view. Accordingly, we can also observe that all genres recontextualize prior texts and discourse from the genre system. Recontextualization is 
what happens when some part or aspect of a genre is taken out of its original context and fit into a new one, such as another text or discourse genre with its own particular use and environment (Linell 1998: 145). Because of its relationship to prior discourse, the recontextualized genre is subjected to textual changes, such as simplification, condensation, elaboration or refocusing; shifts in self-presentation, role-relationships or legitimization of authority; or reversals of figure-ground relations, where what is central in one text may become peripheral in another, and vice-versa. ${ }^{5}$ Because of its insistence on the micro-level linguistic changes in text, recontextualization is a complementary component to an analysis of genre system, allowing us a closer view of the relationship between text and context.

\section{Reciprocal structuration and time/space as context}

Another closely-related aspect of context revealed by rhetorical genre theorists is the importance of the individual's role in genre construction and change, as a necessary counterweight to institutional structure. Influential among genre scholars at the beginning of the 1990s, Giddens' $(1979,1985)$ theory of structuration considers human agency and social structure to be implicated within one another, rather than oppositional. This is so because, according to Giddens, people actively produce, reproduce and alter social structures - including such institutions as genres - through ongoing, recursive interactions; by using discourse to draw on and conform to convention, they reconstitute it. Genres as instances of typified language therefore exist, are created, maintained and achieve institutional force, but only because of recursive human “engagement" (Swales 1993).

Set within a "tri-partite" space (cf. Witte 1992) embodied by institutions, dynamic social forces and individuals, such reciprocal structuration is important for understanding how context and the conditions for emerging textual regularities are related. A direct consequence of this binding relationship is, for example, the relative instability of genre. Although genre's textual features may indicate past continuity, their interrelationship with a dynamic context makes them essentially open to variation because each communicative exchange is the sum of a set of variables produced on a space-time continuum. Genre structure is in a state of constant flux because things are different in different circumstances at different places at different points in time. This has led to Schryer's (1993: 200) timely formulation of genre being "stabilized-for-now, or stabilized-enough" to permit genre's usefulness and normalization within a community.

\section{Theoretical limitations of dialogism and structuration}

19 Dialogism and structuration, such as they have been used by Fairclough (1992), Selzer (1993), Yates \& Orlikowski (1992), Bazerman (1994), Berkenkotter \& Huckin (1995) or Schryer (2000), thus present useful analytical frameworks for examining context as the ongoing reciprocity between structure and individuals, as well as the diachronic and synchronic link between genres and their genre systems. Engeström 1995; Russell 1997) sets restrictive limitations on the thoroughness with which 
context can be described using this model, for context must be considered in terms wider than the model can allow for. While dialogism posits that discourse is context, a focus on utterance as the primary unit of analysis blinds us to other, different kinds of context: socio-economic structures of professions or organizations, histories of practice, ideologies, frames of representation, shared background knowledge, physical setting, material practices, interpersonal relations, personal histories, co-text, etc. Moreover, verbal communication is often not the primary goal of interaction, but a facilitating resource used to achieve intent. Consequently, our analysis must focus on something in addition to discourse.

21 Moreover, while Gidden's reciprocal structurational model describes a dynamic tripartite context in which individuals play a fundamental role in the construction, maintenance and transformation of institutional structures, it lacks necessary constraints for it neither really describes the individual nor provides a way of theorizing about identity construction. In addition, because it is clear that not all actions are possible, determining identity becomes crucial for constraining action space. However, with this model, we have no practical tool for tracing the mechanisms by which individual engagement may truly affect generic structure, nor the extent to which such transformative activity is actually possible. What is needed to further consolidate our understanding of context - and ultimately, its relationship to text - is an increasingly complex account of both the social individual as well as the social environment within which he or she evolves.

\section{A system of human activity as context}

22 We can find a partial answer to these challenges in activity theory (Leont'ev 1981; Engeström 1987, 1993), from which rhetorical genre scholars have more recently begun to draw. ${ }^{6}$ In particular, it has been instrumental in inspiring contributions from newer areas of rhetorical genre analysis. By focusing on genre use and production outside of academia and science, such research provides potentially useful insight into the construction of context for the more professional applications of LSP. ${ }^{7}$

Differing from the earlier accounts reviewed here, which focus on something other than individuals, activity theory's concentration on human activity provides a model for observing how people (subjects) use concrete tools - such as genres - to mediate both their purpose (motive, or the trajectory of action) and the object of behavior, or the point in time/space where people "intermingle" within a system. Thus, human behavior and activity, and their material traces such as text, are seen to result from "negotiation and mutual exchange among individuals" (Russell 1997: 509, emphasis added).

Activity theory's usefulness in identifying context lies in how it allows us to trace human activity as individuals' schematized cognition and patterned behavior - such as learned writing patterns - by situating them within systems of social interaction. Examples of such "activity systems" are: family, a religious organization, an advocacy group, a political movement, a course of study, a school, a discipline, a research lab, a profession, and so on (Russell 1997). ${ }^{8}$ It is these activity systems that determine the development and choice of appropriate tools, including genres of text. Individuals and groups use tools ${ }^{9}$ in order to achieve individual motives or carry out an action common to the needs of the group, such as: building a house or school, fighting a fire, running a business, completing and submitting a tax form, filling out a bill of laden, negotiating and drafting a 
distribution agreement, writing an account of geological field research or a set of instructions and safety warnings in accordance with recent regulations, submitting a grant proposal or a conference abstract, or defending a dissertation.

Being inherently dynamic, activity systems are constantly recreated through the microlevel interactions of individuals using tools within specific time-space relations. It is this very "micro-level intermingling of acting individuals" (Berkenkotter 2001: 332) that constitutes the context. Context, as the entire span of individual actions or events that occur within an activity system over time, is therefore an ongoing accomplishment of activity, rather than a mere backdrop for actions or texts or a static social frame. Context is not permanent fact, but "something that continually happens" (Ohman 1976).

Moreover, given its emphasis on the individual, this theory also provides us with the means for reaching an even broader understanding of context, by proposing a model that traces the origin of individual identity. Here, the identity of both individuals and groups is conceived of in social terms, as the history of their involvement with various social groups, or activity systems. Individual identity - i.e., the uniqueness of each individual results from the interaction between a person's idiosyncratic features and particular history of involvement with multiple activity systems over time (Russell 1997).

By tracing interactions among individuals within a network while they use material tools to accomplish what they must, inseparable from collective, ongoing action, activity systems give materiality to the idea that genres integrate both text and context. By providing a model for context, where we observe how people come together and "intermingle", we can better view the mechanisms by which their interactions will over time produce linguistic typifications and change. Although it is not without its own limitations, some of which will be addressed below, activity theory provides a practical lens for examining the relationship between text and context, by bringing together human activity, motives, individual cognition, socialization, patterned and unpatterned dialogical interaction, and "chronotope" 10 into a coherent whole.

\section{Habitus and sociological constraints on identity as further elements of context}

Although some rhetorical genre theorists claim that an activity theory model of genre accounts for "social-psychological stability, identity and predictability" (Russell 1997: 515), it is in this very claim that we can see its limitations for ultimately describing context. While it usefully provides a model for understanding how people "intermingle" and what happens as a result, activity theory pays only incidental attention to the nature of the system's hierarchical structure. By failing to set coherent constraints upon the system's internal structure in accounting for its hierarchy, it does not adequately describe the system's boundaries and limitations. Notably, it cannot predict why all individuals do not have the same capacity to act upon and within the system, nor across systems.

Relatedly, as a cognitive model, activity theory predicts that identity results from one's involvement with different activity systems over time. However, it does not provide us with a suitable explanation for the conditions under which identity takes shape, especially in terms of the system's internal structural constraints. Issues of structural identity are particularly relevant to applied research in LSP, because they inform us 
about local activity and variations in specialized discourses that make applying a more general - and often Anglo-Saxon - model to teaching haphazard at best. A more thorough description of identity is therefore necessary for understanding how models, such as linguistic descriptions of genre, can be adapted to local contexts.

An increasing number of genre scholars have adopted Bourdieu's $(1980,1984)$ description of institutional structure and identity construction, explained by his formula for describing and predicting human social behavior: "[(habitus)(capital)] + field = practice]" (Bourdieu 1984: 101). Habitus, as a durable set of cognitive and affective dispositions - an individual's "habits of the heart" - is described as being rooted in early socialization. It is a conservative force, linked to what Bourdieu calls doxa - "an uncontested acceptance of the daily lifeworld" (Bourdieu \& Wacquant 1992: 73), through which cultural processes are experienced as though they were natural.

31 The world's "naturalness" stems from the construction of the self taking place below the level of consciousness, "where the body mimics what it performs" (Bourdieu 1980: 73, original emphasis). The body's knowledge of typical and appropriate performance is acquired through the sedimentation of the particular socio-historical forces that affect it. Accordingly, habitus, as an individual's identity, is constructed within the social conditions in which we are raised, acculturated and inculcated. We learn how to walk down the street, talk, behave in school, or appreciate a work of art or music by mimicking those around us. Later, we unconsciously reproduce the "social tastes" we have acquired as children. Although our habitual preferences are adapted to social position, for the most part they are not consciously chosen. Instead, Bourdieu refers to habitus as a practical and intuitive "feel for the game".

Important for our purposes here, the cultural conditions that produce habitus are in no way arbitrary or alterable at whim, and their socially structured effects are abiding. While individuals may at times appear to have a free choice in acting and therefore seem not to conform to "past conventionalized regularities", in reality their actions are constrained. This is so because only certain choices are made available by the cultural system, and these choices are restricted by the limits of one's habitus (Bourdieu 1980: 54-55). Thus, while action at any level may be driven by personal motives, the conditions that allow for effective action are permitted only by one's habitus and its corresponding social value, or rank, in the social hierarchy - one's capital.

Bourdieu's account provides a socially structured explanation for the construction of individual identity and capacity for purposeful action within a system, both of which are intimately tied to the confines of socially authorized and structured space. We can see that the bind between innovation and non-conformity, on the one hand, and social structure and habitus, on the other, is much stronger than suggested by Leont'ev (1981) and Engeström's $(1987,1993)$ model of social action. The concepts of habitus and capital effectively close the gap between the wide-open spectrum of possible action under activity theory and what can be realistically expected, as system-authorized action. Identifying the structural mechanisms that make action effective highlight the importance of social identity: we do not simply use genre as 'a tool' to fulfill a motive, for even the very way in which we use and understand genre is already conditioned by the nature of our cultural and social backgrounds, and identities. 


\section{Integrating text and context as genre}

34

Through this review of recent work to integrate sociological and socio-cognitive theories into an understanding of context, it is argued that in order to gain a richer understanding of genre's complexities - such as the materialization of both textual and contextual patterns, their interrelationship, and how they are equally important to the emergence of specialized language competence - no single "theory" is sufficient for the task. Rather, it is only by drawing from the accumulation of assimilated knowledge and insight produced by successive theories that we can hope to begin unwinding and revealing genre's multifarious fabric. Genre theory, then, necessarily continues to be a resolutely crossdisciplinary endeavor. And so it must remain.

What we have seen here is a useful broadening of the concept of context among genre theorists, moving progressively from immediate "dialogue as context" to wider issues of intertextual links over time, related to institutionalized structures. What has also emerged is the crucial role played by individuals in constructing context, by acting together within social systems. Such intermingling both reinforces and challenges the stabilization of behaviors, the normalization of motives and the textualization of genre. Its mechanisms further inform us about the effects of environment and hierarchical structure on individual identity over time. Ongoing identity construction, as children and adults, motivates our patterned linguistic responses to specific situations as we apply behaviors and strategies learned in contact with multiple social systems.

Issues of identity are a crucial part of the balance for LSP, for in order for a genre to be truly "mastered", its embedded textuality and contextuality must become embedded within individual identity. By identifying themselves with the social group culture, individuals come to "possess" the linguistic and cultural schemata that will allow them to function as recognized members of the community. Only when these generic schemata are in the individual's possession can she or he move beyond mere genre "reproduction", from outside the community, to actively re-creating the genre within the community.

As a result, we move far beyond viewing genre as a mere set of formally definable textual features that certain texts have in common across various contexts. Instead, the concept of genre captures how a multitude of complex, ongoing processes interact. It reflects the process of structuration, whereby a group of more or less divergently-motivated individuals are brought together and end up sharing a configuration of similar thought processes, ways of seeing, practices, social structures, cultural patterns and habitus. These shared configurations are reflected in the discourses they use. Genre shows us text, and it implies context.

\section{Directed Communicative Modeling: An integrated genre approach for teaching LSP}

An integrated theory of genre is ripe with possibilities for designing teaching strategies that more comprehensively develop the full range of competencies needed by students in LSP, and that linguistic, sociological and socio-cognitive research tells us characterizes behavior in specific settings. 

integrated genre approach to teaching. ${ }^{11}$ The approach described here, "Directed Communicative Modeling", builds on these earlier contributions by working rhetorical genre theory's view of context into the dynamics of the classroom. As a consequence, the approach relies as much on building contextual knowledge as it does on building textual knowledge. Indeed, learners' future success in the professional world depends as much on their capacity to manipulate the content, form and structure of their communication as on their knowledge of when and how to place it - or not - within a more or less normalized stream of communication; they must also know how to fit their communication within the expectations of the discourse community. Learning a community's expectations and developing professional competence is a process of ongoing socialization, through continued contact with the community's cultural and linguistic patterns and schemata.

Having specialized language competence is therefore all about learning to manipulate and inventively recreate language structure, within a context that embodies a nexus of identity, social mechanisms, ideology, and institutional structure. Integrated genre's power for the LSP classroom lies in its potential for constructing the wide range of specialized knowledge structures involved in professional language use. Using a conception of genre that integrates text-and-context, the teacher can create situations whereby students are able to experience ways of thinking, acting, being and communicating that are emblematic of the communities they will be entering.

41 To be sure, the classroom cannot hope to replicate the context of the professional workplace, which would be both highly unrealistic and impractical (Dressen 2004), but it can present aspects of context we can theorize about, deconstruct, analyze, and ultimately recreate, using text. In this way, we can engage students in "hands on" activities, whereby professional ways of thinking and using language can be cultivated using genre. Such purposeful language learning engages students in meaningful activities where genres are integral to the task at hand, as "tools-in-use" rather than as mere ends. Viewing genre's potential in this way opens up the door for effectively capitalizing on what a genre approach has to offer to the LSP classroom:

People who use tools actively rather than just acquire them... build an increasingly rich, implicit understanding of the world in which they use the tools and of the tools themselves. The understanding, both of the world and of the tool, continually changes as a result of their interaction. (Brown, Collins \& Duguid 1989: 33)

Integrating both text and context into the classroom calls for a three-step preparation before actual teaching. The following levels of analysis synthesize the research in genre and LSP presented in the earlier parts of this article:

\section{Needs analysis}

In line with long-standing practices in LSP and genre pedagogy, designing well-targeted material requires that the precise needs of the classroom audience be determined. Notably, we need to ask who the student population is and what their backgrounds are; what professional experiences and cultural/textual activities they will they be most likely to encounter; what type of social environment they will come into contact with, and what effect this will have on the development of their social and personal identities.

\section{Textual analysis}


44 regularities in the discourse. In addition to identifying the professional genres students will be using, it is also necessary to identify the genres' linguistic and discoursal structure, including their specific grammatical structures, appropriate register and semantically associated vocabulary, their sequential, move structure, the moves' implicit rhetorical value(s), and corresponding linguistic expressions used to express them.

\section{Contextual analysis}

However, in order to restore meaning to the disembodied genres we are teaching, it is also necessary to analyze the context whose reality the genres translate. Beginning with a description of the social system students will eventually be involved in (academia, industry, technology, small or large private business, government, the media, etc.), we can work toward an increasingly detailed account of the context, by focusing on issues of local identity and social fabric. In addition, we might also ask such questions as: What are the socio-historical explanations for the texts' features? Why do community members express themselves as they do in specific contexts? What do their expressions mean - or implicitly signify? Who is the targeted community, what do they do and what meaning do their situated activities have (e.g., Dressen 2003)?

The results of these different levels of analysis can then be reframed within a pedagogical model, such as Directed Communicative Modeling. This is a three-part genre approach that combines the direct teaching of formalized structures (genre's text), background discussion, role play and task-based scenarios (genre's context), and the progressive modeling of normalized structures through a process of ongoing communication (dialogue )$^{12}$.

While there is some discussion among rhetorical genre scholars over whether the direct teaching of formalized structures is truly useful (Coe 1994, Chapman 1999) ${ }^{13}$ the emphasis placed on explicit language learning within the LSP context makes the direct teaching of specialized discourses' formalized features necessary. Concretely focusing on the formalized features of specialized discourses, such as their lexical, grammatical, and discoursal patterns, allows learners to better predict experienced users' linguistic knowledge and habits. By taking advantage of this knowledge early on, learners may create texts that better conform to community expectations, thereby facilitating interaction with new discourse communities. The aim is to help learners to become "operational" more quickly, an avowed concern for students coming out of professional programs who hope to integrate the professional world as quickly as possible. ${ }^{14}$

The introduction of context into the classroom, using topic-oriented discussions, readings and role-play activities, seeks to pinpoint the situational contingencies involved in genre use. The genre model recreates these contingencies by making explicit the sort of background knowledge that experienced genre users implicitly bring to the communicative task. Such implicit knowledge includes textual genre knowledge, of course, but it is also contextual: sociological, historical, rhetorical, structural, ideological, and situational.

49 In addition to using classroom discussion and readings, context can also be worked into the classroom through the use of scenarios, or scene-setting stories that set up students' use of genre. Scenarios provide the information necessary to creating a text as if in an authentic, communicative situation. They push students to re-create genres, for students must strategically apply their knowledge of the formal structures (lexical, grammatical, 
discoursal) they have learned, as well as the various background, contextual knowledge structures they have assimilated. Strategically planning for an authentic communicative act and imagining the exigencies of the task are possible only if the audience and motivation for the communication are clearly defined through context, and students can identify with this context.

Finally, by integrating aspects of the "process approach" to writing, linguistic and contextual competence are progressively modeled and shaped through an ongoing dialogue between student and teacher, and with other students. In this way, students come to gradually produce more "authentic" texts by progressively re-shaping them as a response to a conversation. In the process they learn to make their texts more audienceoriented and predictable by coming to rely on both the textual patterns and the contextual knowledge structures that have normalized within the classroom, and which are intended to reflect those of the targeted professional community.

\section{Using an integrated genre approach in the classroom}

51 This approach aims to recreate, in some sense, the conditions under which we develop specialized language competence in professional settings, where we are simultaneously exposed to specific, stabilized linguistic patterns and to cultural schemata, all of which are modeled, transferred, shaped, assimilated and challenged through dialogue.

To illustrate some of the key ideas developed here, in the following section I will describe how I have used Directed Communicative Modeling to integrate text and context into a 15-week ESP course where legal and contractual English was taught to fourth-year university students enrolled in a professional degree program. ${ }^{15}$

The students in the course were doing their majors in the commercial, foreign trade and legal aspects of our applied foreign languages program. With an emphasis on the AngloSaxon legal system and contract law, the course was geared toward meeting the students' specific needs, namely, working in international trade and/or transport. There was thus a good probability that, in addition to typical business communications, they would also be responsible for managing shipments and product distributions, developing distribution networks, negotiating with foreign companies and drafting contracts. ${ }^{16}$ They therefore needed to have more knowledge about specialized language than just "Legal English" in general, by seeing how this type of discourse related to their domain of specialty. They needed specifically to see how the textual genres they would be using actually worked in context.

Because one of the primary purposes of the class was to heighten students' critical awareness of their domain's specific linguistic features, we began the semester by explicitly addressing what it is that makes discourses specific. To begin, we analyzed an example of scientific discourse as a group, whose context I first retold as a narrative. ${ }^{17} \mathrm{At}$ the end of discussion, students were able to see - a little bit, at least - what underlying stories had shaped the features of the language. This sort of contextual understanding, I told them, was where I wanted them to go over the course of the semester. However, I knew the getting there was going to be slow, where the progression of the course was going to be like laying bricks, or "scaffolding" (Donato 1994, Riley 2003). The foundations of text and context needed to be set, but could only be done so progressively. 
The following week, we began to introduce the textually concrete aspects of genre, by addressing some of the specialized vocabulary students would need to become familiar with in order to be comfortable working with the formal, functional and legal aspects of contracts. By introducing the vocabulary early on through various exercises, I hoped to move beyond having it act merely as wordlists to be learned and stored temporarily in short-term memory. Instead, I wanted the vocabulary to become integrated into their active knowledge, endowed with a specialist network of meaning.

These early textual elements were to be sustained by a more contextual complement. Accordingly, I simultaneously began conducting a series of backgrounding lectures ${ }^{18}$ on the foundations to the Anglo-Saxon law system, its socio-historical development, the origin and importance of the practice of "precedent", its relationship to contract law, and how this is all generally translated into the linguistic and discoursal structures we find in legal documents such as contracts. To give them a break from note-taking and passive listening, and to help them concretize lecture information into active "knowledge" (Felder \& Brent 2003), in class they were also asked to solve basic contractual problems by applying their understanding of the vocabulary and course lectures on contract law. Some of the problems involved determining why particular contracts were considered problematic, what would happen to a contract if it were contracted by a minor or if war broke out, etc.

Over the coming weeks, I alternately added elements to the generic nebula by going back and forth between context and text, building up the scaffolding for their targeted recreative use of contractual English. To continue emphasizing the textual, we worked on genre's discoursal structure, and they were asked to identify the forms and functions of various legal documents. In addition, we worked specifically on the sequential structure of legal documents, following the model outlined by Butt and Castle (2001: 131). ${ }^{19} \mathrm{We}$ further addressed the linguistic differences between formal and informal English, their corresponding Anglo-Saxon and Latinate roots, and how this is reflected in legal English.

Within this textual backdrop, the group was asked to read a book chapter ${ }^{20}$ which described the development of legal drafting by looking at the various historical, social and linguistic influences. I was aiming at moving them beyond the mere recognition that legal English is full of archaic forms, cumbersome word order and convoluted style. In order to "demystify" the legal text, I wanted them to understand the why and to become critically analytical of it, so as to take better possession of the text's underlying context. As such, I was targeting a multiple range of input, ranging from oral listening skills, to reading, to in-class dialogical application to reflective written homework exercises.

At this point, approximately midway through the semester, I began to consciously draw together the different bits and pieces of the contextual and textual puzzle by zeroing in specifically on our class's targeted professional genre - the contract. From the multitude of contracts we might have worked on, the Distribution Agreement served as a platform for integrating the contractual genre's multifarious context. My choice was further motivated by the types of experiences these students would likely have in the workplace. Accordingly, they were asked to read a number of Distribution Agreements, first for meaning and to respond to a series of questions on content. Next, we began working more and more closely on applying their contextual and textual knowledge, by identifying the function and meaning of each provision, and determining its underlying legal context. Each week they were to have prepared a contract assigned as homework, and we would go through each with a fine-toothed comb, identifying function, the legal context, and 
pinpointing the specific features of its language. Here, they were asked to analyze and apply their knowledge of the specific vocabulary, linguistic structures, legal concepts, discoursal move structure, probable situation of use and underlying rhetorical assumptions. Along the way, we were able to broach broader issues in context, such as areas of unclear drafting, where implicit wordings could potentially lead to difficulties in cases of dispute, as well as how the wording at times belayed an unbalanced power relation between the parties - traps they might like to avoid.

The scaffolding was nearly finished and I was about to alter my role in the classroom, moving from knowledge-giver to counselor. We were set to begin work on a class project, which would span out over a period of five weeks - the negotiation of a Distribution Agreement between an American manufacturer and a French distributor. I saw several heads nod as they, too, began to see it all come together. We spent a good part of the class period discussing how everything we had been working on over the semester was to be reflected in this final project: the linguistic and discoursal structure of contractual English, the ramifications of contract law on drafting, the specific workplace situations in which they would encounter such activities, etc. They were to go home that week with some more contextual reading about international negotiation strategies and the culture of American business and negotiation practices, with the added assignment of reflecting on how this might contrast with their own culturally oriented practices.

61 For the actual negotiations, the students divided up into small groups of 4-6 people, and then further into two teams, one representing the American company's interests, the other the French. Their task, as established by a scenario, was to hammer out an agreement for the distribution of mid-range golf equipment in France. The equipment was manufactured by a successful American company, who wished to create a solid market opening in different localities in Europe, including France. While the overall French golf market was small, there was a growing demand for golf equipment especially in certain French overseas territories. The French distributor, on the other hand, was looking to consolidate its market share by upscaling its product quality. The two teams were to come to an agreement over a number of fixed points reflecting the scenario, and that would ultimately need to figure in the final contract: commission rate, possibility of price modifications, exclusivity of distributorship, responsibility for advertisement and shipping expenses. ${ }^{21}$

Within the framework of this final project, the class suddenly came roaring to life as students began actively applying the texts and contexts they had assimilated. In addition to our course, this included relying on their previous professional experiences as well as on content from other courses in the program where they had studied European law, market strategies, distribution networks, logistics, international trade practices and company prerogatives. By playing on their cross-disciplinary theoretical knowledge, the project allowed them to bring the two parts of their specialist knowledge together. The door was opened for language to become a tool in getting things done rather than simply to be learned. In consequence, as they took possession of their knowledge, they assumed new and very "professional" identities. As I listened in on earnest negotiations, I observed that they had stopped acting the - rather passive - role of students in the classroom, as receivers of knowledge, and had fully entered the role play. They had become negotiators.

But this was just the beginning. Once the passions had cooled off after their sometimes intense meetings, and they had objectively analyzed the relative success of their negotiation strategies by presenting them to the class in an oral presentation, the next 
step was to get it all down in writing. When they began to draft their agreement as a group, however, they quickly realized that their negotiations hadn't taken care of all the issues raised and left unresolved. Tensions rose once again as each team maneuvered to make sure that their priorities were carefully inscribed in writing. My role, during this period, had become one of consultant rather than teacher. I, along with all my structured information, had moved to the periphery of the classroom as the carefully-laid scaffolding fell aside and they took charge of assimilating what they had learned. I moved from group to group, providing support as they grappled with whether or not they could actually say and do what they wanted.

The next week they were to turn in a first version of the contract. Their contracts would be graded on the use of correct language and register, clear and logical sequential structure, legal soundness (including having all appropriate provisions and clearly worded intentions), and finally, it had to be original. As I explained, although it was perfectly acceptable to use the contracts we had studied as models, much as people do in work organizations where they adopt previous contracts as templates, they needed to move away from merely copying other contracts, which often results in useless provisions, unclear wording, and incomprehensible intentions. ${ }^{22}$ They were to reshape previous contracts into a document that would fit the specific context of their own negotiations. After churning out their insides, they handed in the first version of their contracts, visibly pleased with themselves and their effort.

The next step was then to take their initial drafts and remodel them into "normalized" documents. Over the next few days, I carefully read through and marked their papers, where the greatest problems had to do with ambiguity in language, miswording, and absent legal barriers. Rather than just marking their mistakes, I wrote to them the why of what would make their drafts more suitable for a professional context - the answers to which were to be found in all the context they'd been given over the course of the semester: legal, practical, pragmatic, linguistic, rhetorical, etc. I challenged them to be accountable for what they had written.

The next class period was spent entirely going over the comments I had made on their drafts, where they alternated between avid discussions over what to change and theoretical questions to me about how they could change things, what it would mean and why I'd said what I had. Rather than passively taking in my explanations, they purposefully sought them out and worked to shape my information into the textual strategies they needed to make their texts do what they wanted. They were actively integrating knowledge of both text and context into their re-creation of the genre, and to me, clearly possessed both multiple strategies for solving problems as well as the means for achieving their ends. After the semester-long exercise of getting themselves into the "mind frame" of what it means to have specialized professional competence, they were assimilating and re-producing the textual and contextual patterns that allowed them to re-create professional-feeling and -looking documents. For a brief moment at least, they were no longer on the outside looking in but were active meaning makers of genre.

\section{Conclusion}

67 This is but one description of how an integrated view of genre might be applied to developing multiple competencies in the LSP classroom. It integrates assumptions about the social conditions in which we learn specialized discourses, as well as what makes 
specialized discourses "specific". By recreating situations that capitalize on these assumptions, it aims to get students to understand that language is a tool and that we can identify and understand its mechanisms - textual and contextual - so as to use it more efficiently. In other words, we can begin to use genre as those "in the know" rather than merely as those "on the outside looking in", a goal which goes to the very heart of genre pedagogy.

There is clearly much to be said about adapting largely Anglo-Saxon teaching practices to the specificities of the French university system. ${ }^{23}$ It is clear that a praxis approach founded in critical pedagogy, well-suited to working with smaller, knowledge producing groups, is set to collide with a system of large university classes conditioned to reproducing knowledge, with little time - or patience and energy - left over to invest in the discovery of meaning-making processes and the "re-production" of specialized genres. My experience here, however, has shown me that French students can become receptive to such an approach - indeed, their transformation was radical. However, a successful adaptation of the genre approach in non Anglo-Saxon environments must rely on a process of "localization", where a careful analysis of local institutional context and cultural identity is crucial. In order for genre to come to life in the classroom as text-andcontext, re-embodied by students, we as teachers must also critically evaluate and integrate local place into the balance of our own understandings of genre.

\section{BIBLIOGRAPHY}

Anderson, J., Reder, L. \& H. Simon. 1998. "Radical constructivism and cognitive psychology". In D. Ravitch (ed.), Brookings Papers on Education Policy. Washington, D.C.: Brookings Institution Press, 227-278.

Artemeva, N. \& A. Freedman. 2001. “'Just the boys playing on computers': An activity theory analysis of differences in the cultures of two engineering firms". Journal of Business and Technical Communication 15, 164-194.

Atkinson, D. 1999. Scientific Discourse in Sociohistorical Context. Mahwah, NJ: Lawrence Erlbaum. Bakhtin, M. 1981. The Dialogical Imagination. Austin: University of Texas Press.

Bakhtin, M. 1986. Speech Genres and Other Late Essays. Austin: University of Texas Press.

Banks, D. 2002. "Systemic Functional Linguistics as a model for text analysis". ASp 35-36, 23-34.

Barber, C. 1962. "Some measurable characteristics of modern scientific prose". In Contributions to English Syntax and Philology. Göteborg: Amqvist \& Wiksell, 21-44. Reprinted in J.M. Swales (ed.). 1988. Episodes in ESP.

Barton, E. 2002. “Inductive discourse analysis: Discovering rich features”. In E. Barton \& G. Stygall (eds.), Discourse Studies in Composition. Cresskill, NJ: Hampton Press, 19-42.

Bazerman, C. 1988. Shaping Written Knowledge: The genre and activity of the experimental article in science. Madison: University of Wisconsin Press. 
Bazerman, C. 1994. "Systems of genres and the enactment of social intentions". In A. Freedman \& P. Medway (eds.), Genre and the New Rhetoric. Bristol, PA: Taylor \& Francis, 79-101.

Bazerman, C. 1997. "Discursively structured activities". Mind, Culture \& Activity 4, 296-308.

Beaufort, A. 2000. "Learning the trade: A social apprenticeship model for gaining writing expertise”. Written Communication 17, 185-223.

Berkenkotter, C. 2001. "Genre systems at work: DSM-IV and rhetorical recontextualization in psychotherapy paperwork". Written Communication 18, 326-349.

Berkenkotter, C. \& T. Huckin. 1995. Genre Knowledge in Disciplinary Communication: Cognition/ culture/power. Hillsdale, NJ: Lawrence Erlbaum.

Bhatia, V. 1993. Analysing Genre: Language use in professional settings. London: Longman.

Bhatia, V. 1995. “Applied genre analysis and ESP”. TESOL France 2, 161-179.

Biesenbach-Lucas, S. 1995. "Three approaches to textual analysis: A chronological review of research in EST". (manuscript)

Bourdieu, P. 1980. The logic of Practice. Cambridge, UK: Polity Press.

Bourdieu, P. 1984. Distinction: A social critique of the judgment of taste. Harvard: Harvard University Press.

Bourdieu, P. \& L. Wacquant. 1992. An Invitation to Reflexive Sociology. Cambridge, UK: Polity Press.

Brown, J., Collins, A. \& P. Duguid. 1989. "Situated cognition and the culture of learning".

Educational Researcher 18, 32-42.

Butt, P. \& R. Castle. 2001. Modern Legal Drafting: A guide to using clearer language. Cambridge, UK: Cambridge University Press.

Candlin, C. 1996. "General editor's preface”. In W. Grabe \& R. Kaplan, Theory and Practice of Writing . London: Longman.

Chapman, M. 1999. “Situated, social, active: Rewriting 'genre' in the elementary classroom”. Written Communication 16, 469-490.

Coe, R. 1994. “Teaching genre as process". In A. Freedman \& P. Medway (eds.), Learning and Teaching Genre. Portsmouth, NH: Heinemann.

Cutts, M. 1996. Plain English Guide: How to write clearly and communicate better. Oxford: Oxford University Press.

Devitt, A. 1991. “Intertextuality in accounting”. In C. Bazerman \& J. Paradis (eds.), Textual Dynamics of the Professions. Madison: University of Wisconsin Press, 336-357.

Dias, P., Freedman, A., Medway, P. \& A. Paré. 1999. Transitions: Writing in academic and workplace settings. Mahwah, NJ: Lawrence Erlbaum.

Donato, R. 1994. "Collective scaffolding in second language learning”. In J. Lantolf \& G. Appel (eds.), Vygotskian Approaches to Second Language Learning. Norwood, NJ: Ablex.

Dressen, D. 2002. "Identifying textual silence in scientific research articles: Recontextualizations of the field account in geology". Hermes 28, 81-107.

Dressen, D. 2003. “Geologists' implicit persuasive strategies and the construction of evaluative evidence". Journal of English for Academic Purposes 2, 273-290. 
Dressen, D. 2004. "La modélisation communicative dirigée: l'apport de la démarche de genre à l'enseignement de l'anglais professionnel”. Les Cahiers de l'APLIUT 23, 1-15.

Dudley-Evans, T. 1995. "Common-core and specific approaches to the teaching of academic writing”. In D. Belcher \& G. Braine (eds.), Academic Writing in a Second Language. Norwood, NJ: Ablex, 293-312.

Dudley-Evans, T. \& M.-J. St. John. 1998. Developments in English for Specific Purposes: A multidisciplinary approach. Cambridge, UK: Cambridge University Press.

Duranti, A. \& G. Goodwin (eds.). 1992. Rethinking Context: Language as an interactive phenomenon. Cambridge, UK: Cambridge University Press.

Eggins, S. \& J.R. Martin. 1997. “Genres and registers of discourse”. In T. van Dijk (ed.), Discourse as Structure and Process. London: Sage, 230-256.

Engeström, R. 1995. "Voice as communicative action". Mind, Culture and Activity 2, 192-215.

Engeström, Y. 1987. Learning by Expanding: An activity-theory approach to developmental research. Helsinki: Orienta-Konsultit Oy.

Engeström, Y. 1993. "Developmental studies of work as a testbench of activity theory: The case of primary care medical practice”. In S. Chaiklin \& J. Lave (eds.), Understanding practice: Perspectives on activity and context. Cambridge, UK: Cambridge University Press, 64-103.

Fairclough, N. 1992. Discourse and Social Change. Cambridge, UK: Polity Press.

Felder, R. \& R. Brent. 2003. “Doing by learning”. Chemical Engineering Education 37, 282-283.

Freedman, A. 1999. "Beyond the text: Towards understanding the teaching and learning of genres". TESOL Quarterly 33, 764-767.

Freedman, A. \& P. Medway (eds.). 1994. Genre in the New Rhetoric. Bristol, PA: Taylor \& Francis. Garner, B. 2001. Legal Writing in Plain English: A text with exercises. Chicago: University of Chicago Press.

Geisler, C. 2001. "Accounting for the role of texts in the everyday life of complex organizations". Written Communication 18, 296-325.

Giddens, A. 1979. Central Problems in Social Theory: Action, structure, and contradiction in social analysis. Berkeley: University of California Press.

Giddens, A. 1984. The Constitution of Society: Outline of the theory of structuration. Cambridge, UK: Polity Press.

Gunnarsson, B.-L. 1997. “The writing process from a sociolinguistic viewpoint”. Written Communication 2, 139-188.

Gunnarsson, B.-L., Linell, P. \& B. Nordberg (eds.). 1997. The Construction of Professional Discourse. London: Longman.

Günthner, S. \& H. Knoblauch. 1995. "Culturally patterned speaking practices: The analysis of communicative genres". Pragmatics 5, 1-32.

Halliday, M. \& R. Hasan. 1985. Language, Context and Text: Aspects of Language in a Social-Semiotic Perspective. Oxford: Oxford University Press.

Halliday, M., McIntosh, A. \& P. Strevens. 1964. The Linguistic Sciences and Language Teaching. London: Longman.

Huckin, T. 1997. “Cultural aspects of genre knowledge”. AILA Review 12, 68-78. 
Huckin, T. 2002. "Textual silences and the discourse of homelessness". Discourse and Society 13, 347-372.

Hyon, S. 1996. “Genre in three traditions: Implications for ESL”. TESOL Quarterly 30, 693-722.

Hyland, K. 2000. Disciplinary Discourses: Social interactions in academic writing. Harlow, UK: Longman.

Ivanic, R. 1998. Writing and identity: The discoursal construction of identity in academic writing.

Amsterdam: John Benjamins.

Johns, A. 1995. "Teaching classroom and authentic genres: Initiating students into academic cultures and discourses". In D. Belcher \& G. Braine (eds.), Academic Writing in a Second Language: Essays on research and pedagogy. Norwood, NJ: Ablex, 277-291.

Johns, A. 1997. Text, Role and Context: Developing academic literacies. New York: Cambridge University Press.

Kress, G. 1993. “Genre as social process”. In B. Cope \& M. Kalantzis (eds.), The Powers of Literacy : A genre approach to teaching writing. Hong Kong : The Falmer Press, 22-37.

Lapaire, J.-R. \& W. Rotgé. 1992. Réussir le commentaire grammatical de texte. Paris: Ellipses.

Lassen, I. 2003. Accessibility and Acceptability in Technical Manuals. Amsterdam: John Benjamins.

Leont'ev, A. 1981. “The problem of activity in psychology”. In J. Wertsch (ed.), The Concept of Activity in Soviet Psychology. Armonk, NY: Sharpe, 37-71.

Linell, P. 1998. "Discourse across boundaries: On recontextualizations and the blending of voices in professional discourse". Text 18, 143-157.

Magnet, A. 2001. "Diachronic analysis of the visuals in the research paper: A corpus-based study of the strategies and semiotics of visual representation in nutrition biochemistry". LSP \& Professional Communication 1, 55-77.

Martin, J.R. 2000. "Beyond exchange: Appraisal systems in English". In S. Hunston \& G. Thompson (eds.), Evaluation in Text: Authorial stance and the construction of discourse. Oxford, UK: Oxford University Press, 142-175.

Miller, C. 1984. “Genre as social action”. Quarterly Journal of Speech 70, 151-167.

Nystrand, M. 1986. The Structure of Written Communication: Studies in reciprocity between writers and readers. Orlando, FL: Academic Press.

Ohmann, R. 1976. English in America: A radical view of the profession. New York: Oxford University Press.

Prior, P. 1997. "Literate activity and disciplinarity: The heterogeneous (re)production of American studies around a graduate seminar". Mind, Culture and Activity 4, 275-295.

Prior, P. 1998. Writing Disciplinarity: A sociohistoric account of literate activity in the academy. Mahwah, NJ: Lawrence Erlbaum.

Räisänen, C. 1999. The Conference Forum as a System of Genres. Gothenberg, Sweden: Acta Universitatis Gothoburgensis.

Ravotas, D. \& C. Berkenkotter. 1998. "Voices in the text: Varieties of reported speech in a psychotherapist's notes and initial assessments". Text 18, 211-239.

Riley, P. 2003. "De l'instruction à la construction: apprentissage par les tâches, médiation sociale et développement personnel”. Plenary presented at XXV Congrès de l'APLIUT, Auch, France, 5 7 June, 2003. 
Rodgers, D. 1998. Business Communications: International case studies in English. Cambridge, UK: Cambridge University Press.

Russell, D. 1997. "Rethinking genre in school and society: An activity theory analysis". Written Communication 14, 504-554.

Salager-Meyer, F. 1998. "Le discours aigre-doux de la controverse scientifique: Évolution de la rhétorique des confrontations académiques”. ASp 19-22, 29-50.

Schryer, C. 1993. "Records as genre”. Written Communication 10, 200-234.

Schryer, C. 2000. "Walking a fine line: Writing negative letters in an insurance company". Journal of Business and Technical Communication 14, 445-497

Selzer, J. 1993. “Intertextuality and the writing process: An overview”. In R. Spilka (ed.), Writing in the Workplace: New research perspectives. Carbondale: Southern Illinois University Press, 171-180.

Swales, J.M. 1988. Episodes in ESP: A source and reference book on the development of English for science and technology. New York: Prentice Hall.

Swales, J.M. 1990. Genre Analysis: English in academic and research settings. Cambridge: Cambridge University Press.

Swales, J.M. 1993. “Genre and engagement”. Revue Belge de Philologie et d'Histoire 71, 687-698.

Swales, J.M. 1998. Other Floors, other Voices: A textography of a small university building. Mahwah, NJ: Lawrence Erlbaum.

Swales, J.M. 2000. "On models in applied discourse analysis". Plenary presented at Conference on Discourse in the Professions, City University, Hong Kong, November 2000.

Swales, J.M. \& C. Feak. 1994. Academic Writing for Graduate Students: A course for nonnative speakers of English. Ann Arbor: University of Michigan Press.

Swales, J.M. \& C. Feak. 2000. English in today's Research World: A writing guide. Ann Arbor: University of Michigan Press.

Taillefer, G. 2002. "L'anglais dans les formations spécialisées à l'université : un cheveu sur la soupe? Peut-on rendre la plat plus appétissant?”. ASp 37-38, 155-166.

Tracy, K. 1998. “Analyzing context: Framing the discussion”. Research on Language and Social Interaction 31, 1-28.

Winsor, D. 1996. Writing Like an Engineer: A Rhetorical Education. Mahwah, NJ: Lawrence Erlbaum.

Yates, J. \& W. Orlikowski. 1992. "Genres of organizational communication: A structurational approach to studying communication and media”. Academy of Management Review 17, 299-326.

\section{NOTES}

1. E.g., Goodwin 1994, Bazerman 1994, Berkenkotter \& Huckin 1995 or Swales 1998.

2. In particular, see Duranti \& Goodwin 1992, Engeström 1993, Russell 1997, Linell 1998, Tracy 1998 or Berkenkotter 2001.

3. Such a call has been repeated by a number of genre scholars over the years: Halliday \& Hasan 1985, Kress 1993, Freedman \& Medway 1994, Bhatia 1995, Candlin 1996, Huckin 1997, Johns 1997, Swales 1998, Schryer 2000, Hyland 2000, Berkenkotter 2001 or Barton 2002.

4. For descriptions of genre systems, see Devitt 1991, Bazerman 1994 or Räisänen 1999. 
5. For studies on recontextualization, see Linell 1998, Ravotas \& Berkenkotter 1998 or Dressen 2002.

6. E.g., Bazerman 1997, Prior 1997, Russell 1997, Artemeva \& Freedman 2001 or Berkenkotter 2001.

7. E.g., Dias et al. 1999, Freedman \& Smart 1997, Prior 1997, Winsor 1999.

8. In some minds, the activity system goes conceptually further than discourse community in describing discursive interactions. Despite its undeniable metaphorical practicality, attempts to theorize about discourse community have tended to treat the conditions and contexts of text production as simplified containers. As a result, it has encountered difficulties in explaining the process by which texts come to 'belong' to certain communities (see discussion in Swales 1998).

9. By emphasizing the notion of tool, activity theory sets linguistic tools on an equal footing with other types of tools used to get things done within a community. A genre of text is thus considered to be merely one tool among others used to achieve a motive.

10. Although the term comes from Bakhtin (1986: 84), it is purposefully used here given its usefulness in efficiently expressing the space/time relations that reflect current social beliefs about the placement and actions of human individuals (see also Schryer 2000).

11. See, for example, Cope \& Kalantzis 1993; Swales \& Feak 1994, 2000; Bhatia 1995; Dudley-Evans 1995; or Johns 1995, 1997.

12. Further discussion and a different application of the approach is given in Dressen (2004).

13. A useful addendum to this debate can be found in a recent review of research in cognitive psychology (e.g., Anderson et al. 1998), where various analysts underline the difficulties faced by students exposed to radical teaching approaches without explicit teaching, which leave them to simply 'deduce' structure.

14. For the students coming out of our program, this need is very pressing, indeed. The results of a survey recently conducted by the L.E.A. department at Université Blaise Pascal - Clermont 2 (January 2004, "Suivi des Diplômés de Licence et Maîtrise L.E.A. Promotions 1995 - 2003", p. 41) shows that $65 \%$ our students have landed their first professional position within three months of completing their degree. Another $16.4 \%$ have found placement within an additional three months.

15. The L.E.A. department at the UFR Langues Appliquées, Commerce et Communication, Université Blaise Pascal - Clermont 2. LSP is taught in the third and fourth years of the program, for the purposes of technical communication and specialized translation, international trade and commerce, and the Agro-Business industry.

16. This orientation is confirmed by the results of the survey previously cited (See Appendix: "Répertoire des Emplois - Langues Etrangères Appliquées, Promotions 1995 - 2003").

17. The narrative was based on the account of geological culture described in Dressen (2003).

18. The course was conducted entirely in English. French was used only occasionally to resolve misunderstandings.

19. In particular, Butt and Castle have identified a five-part structure that they found holds for "successful" legal documents in general: introductory matters, the heart of the deal, things associated with the heart of the deal, what happens when things go wrong, and standard provisions.

20. 'What influences the legal drafter', in Butt and Castle (2001: 5-31).

21. The scenario has been adapted from Rodgers (1998: 33-41).

22. Such concerns are at the heart of the Plain English movement for legal drafting (see Cutts 1996, Butt \& Castle 2001, and Garner 2001).

23. See Taillefer (2002) for an insightful evaluation of such a task. 


\section{ABSTRACTS}

The role the genre approach may continue to play in the development of LSP competence is the central issue raised in this paper. If LSP competence means possessing multiple knowledge structures, in addition to linguistic knowledge, then it is suggested that a genre approach, especially as an integration of text-and-context, is particularly well-suited to developing LSP needs. To understand what contributions integrated genre may make, this article first reviews genre theory's recent reconceptualization of context. Using an integrated view of genre as a frame for understanding the conditions for specialized language emergence, it then describes an approach to teaching LSP, called Directed Communicative Modeling. This approach seeks to develop the wide range of competencies needed by students in LSP.

Quelles peuvent être aujourd'hui les contributions d'une approche de genre à l'enseignement des compétences en LSP ? Cet article répond à cette question en suggérant que l'approche de genre y est bien adaptée, surtout si ce que l'on comprend par genre est texte-et-contexte. Afin de mieux comprendre la dualité de genre, la récente reconceptualisation du contexte par des chercheurs en genre sera discutée. Ensuite, s'appuyant sur une vision intégrée de genre afin de mieux cerner et comprendre les conditions du développement de la compétence langagière spécialisée, une approche pour l'enseignement des LSP, appelée la "modélisation communicative dirigée », sera décrite. Cette approche cherche à développer les multiples compétences nécessaires en LSP, en intégrant les suppositions générées par l'unification du texte et du contexte.

\section{INDEX}

Mots-clés: contexte, dialogisme bakhtinien, habitus, modélisation communicative dirigée, théorie de genre unifiée, théorie de la structuration, théorie de l'activité

Keywords: activity theory, context, dialogism, directed communicative modeling, habitus, integrated genre theory, structuration theory

\section{AUTHOR}

\section{DACIA DRESSEN-HAMMOUDA}

Dacia Dressen-Hammouda est maître de conférences en anglais de spécialité à l'UFR LACC à l'Université Blaise Pascal (Clermont 2), où elle travaille avec des étudiants en $2^{\mathrm{e}}$ et $3^{\mathrm{e}}$ cycles en sciences économiques et juridiques, industrie agro-alimentaire et informations scientifiques et techniques. Ses axes de recherche sont la théorie et l'analyse de genre, l'anglais scientifique, technique et professionnel, la rédactologie en L1 et L2, et l'analyse contrasté de l'anglais et du français. Dacia.Hammouda@univ-bpclermont.fr 